\title{
Comparing perinatal outcomes for healthy pregnant women presenting at primary and tertiary settings in South Auckland: A retrospective cohort study
}

\author{
Annabel Farry ${ }^{A, B}$ MHSC, BSC, RM - Judith McAra-Couper ${ }^{B}$ PhD, RM • Mark C. Weldon ${ }^{B}$ PhD - Janine \\ Clemons $^{B}$ PhD, RM
}

${ }^{\mathrm{A}}$ Corresponding Author: annabel. farry@aut.ac.nz

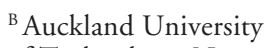
of Technology, New Zealand

\begin{abstract}
Background: Strong evidence supports the premise that many low-risk women and babies experience perinatal outcomes, in a free-standing, midwifery-led, primary level maternity unit (PMU) similar to, or better than, those of an obstetric-led tertiary level maternity hospital (TMH).

Aim: The aim of this study was to identify whether place of birth affected measurable maternal and neonatal outcomes in a low-risk cohort within one New Zealand District Health Board.

Method: We gathered the birth records of a retrospective cohort of low-risk women $(n=4,207)$, who had birthed within two distinct environments, including one TMH and three PMUs. Comparison was made of three maternal outcomes: emergency caesarean section, acute postpartum admission to theatre/high dependency unit/intensive care unit $(<12 \mathrm{hr}$ post birth) and postpartum haemorrhage $(\mathrm{PPH} ;>500 \mathrm{ml})$. Neonatal outcomes analysed were 5-min Apgar score $<7$ and acute neonatal admission to neonatal intensive care unit (NICU; $<12 \mathrm{hr}$ post birth).
\end{abstract}

Findings: Logistic regression of data revealed statistically significant associations between place of birth and the five perinatal outcomes. Low-risk women giving birth in one of the three PMUs had fewer emergency caesarean sections (OR 0.25, 95\% CI, 0.157-0.339), PPHs (OR 0.692, 95\% CI, $0.534-0.898$ ), and acute postpartum admissions to theatre (OR $0.201,95 \% \mathrm{CI}, 0.102-0.398$ ) than women giving birth in the TMH. Babies born to women at a PMU were less likely to experience a 5-min Apgar $<7$ (OR 0.313, 95\% CI, 0.124-0.791) or acute neonatal admission to NICU (OR $0.492,95 \% \mathrm{CI}, 0.324-0.747)$ compared to babies of women of similar risk status, born in the TMH.

Conclusion: Low-risk women birthing in PMUs in South Auckland, New Zealand, experienced a significant reduction in morbidity for themselves and their babies.

Keywords: place of birth, primary birthing unit, tertiary maternity hospital, caesarean section, neonatal morbidity, maternal morbidity, transfer rates

\section{INTRODUCTION}

In Aotearoa New Zealand (NZ) there are currently 54 freestanding primary level midwife-led maternity units (PMUs) either owned by a District Health Board (DHB) or by non-government organisations (Ministry of Health, 2017). These PMUs offer birthing and postnatal facilities. There are also 18 secondarylevel and six tertiary-level obstetric-led maternity hospitals (TMHs) that have specialist obstetric, midwifery, anaesthetic and paediatric services on site (Ministry of Health, 2017). Women in NZ can choose where to give birth. Low-risk women have the options of giving birth in their own home, or in a primary, secondary or tertiary maternity facility. However, access is often an issue as most PMUs are rurally located and many towns and cities with secondary level hospitals have no PMU option. All PMUs, whether private or public, receive government funding for maternity service provision. Self-employed, government funded, Lead Maternity Carer (LMC) midwives provide continuity of care to women irrespective of planned or actual birthplace (Ministry of Health, 2007). This includes intrapartum care in the woman's chosen place of birth, with rostered midwives providing midwifery services in the facilities or in the hospital. It is possible for a private obstetrician to provide primary maternity care as an LMC (at an additional cost to the woman) but if women choose a private obstetrician, a PMU is no longer a birthplace option. At the time of data collection, midwives were the LMC for $93.6 \%$ of women nationally (Ministry of Health, 2015) and for all of the participants in this study. Private obstetric care for low-risk women is rare in this low-decile region (accounting for only $0.6 \%$ of the low-risk births) and is therefore not included in the analysis. The midwives in this study continued as the primary caregiver whether the woman remained in the PMU or was transferred to the TMH for specialist consultation. Accordingly, differences in outcomes presented relate to birthplace independently of model of care. 


\section{BACKGROUND}

Despite the number of primary units available in NZ, the proportion of women choosing to birth in a primary unit has been reducing from $15.6 \%$ in 2007 (Ministry of Health, 2015) to $9.9 \%$ in 2015 (Ministry of Health, 2017). "Safety" is the principle consideration in women's birthplace decision-making, but the way safety is understood differs according to birthplace choice (Grigg, Tracy, Daellenbach, Kensington, \& Schmied, 2014). Women choosing the tertiary hospital setting consider access to specialist services/facilities (if needed) was the most important factor, whereas women planning a primary setting identified "closeness to home", "ease of access", the "atmosphere" of the unit and "avoidance of unnecessary intervention" as important (Grigg et al., 2014). The decreasing utilisation of PMUs may be related to the increase in the number of women experiencing intervention (such as induction of labour, labour augmentation, instrumental assisted birth and emergency caesarean section) across the country (Ministry of Health, 2017).

Undertaking a randomised controlled trial for place of birth is problematic due to the inability to blind participants and clinicians and the need to ensure the woman has informed choice. Hollowell et al. (2011) published a prospective cohort study of women $(n=64,538)$ who gave birth between 2008 and 2010 in England. No significant differences were found in the adjusted odds ratios (AORs) of primary outcome (a composite of perinatal mortality and intrapartum related morbidities) for low-risk women who gave birth in a PMU compared with a TMH (AOR 1.22, 95\% CI, 0.76-1.96). The researchers concluded that choice of birth place had no effect on perinatal outcomes. However, in the TMH, lowrisk women experienced increased rates of intrapartum caesarean section (AOR 0.32, 95\% CI, 0.24-0.42) and birth interventions such as augmentation (AOR 0.26, 95\% CI, 0.20-0.33), epidural (AOR 0.25, 95\% CI, 0.2-0.31), episiotomy (AOR 0.33, 95\% CI, 0.28-0.39), transfusion (AOR 0.48, 95\% CI, 0.32-0.73), admission to higher level care (AOR 0.32, 95\% CI, 0.13-0.84), and third or fourth degree perineal trauma (AOR 0.78, 95\% CI, 0.58-1.05). Another component of this research involved a cost analysis which showed that the use of community-based birthing options is less expensive than hospital-based services (Schroeder et al., 2012).

Further prospective, retrospective and population based studies from Denmark (Overgaard, Møller, Fenger-Grøn, Knudsen, \& Sandall, 2011), the Netherlands (Wiegerinck et al., 2015), Australia (Homer et al., 2014; Laws, Tracy, \& Sullivan, 2010; Monk, Tracy, Foureur, Grigg, \& Tracy, 2014), United States of America (Stapleton, Osborne, \& Illuzzi, 2013) and NZ (Bailey, 2017; Davis et al., 2011; Grigg et al., 2017) reported significantly fewer obstetric interventions (such as instrumental birth, emergency caesarean section, labour augmentation, episiotomy) for mothers and no difference in neonatal mortality and morbidity for babies, when choosing midwifery-led settings (home and PMU) over obstetric-led hospitals. In contrast, population-based studies from the USA report higher neonatal mortality for babies born at home (Grünebaum et al., 2014; Wax et al., 2010) and a higher prevalence of Apgars of 0 at 5-min and neurological dysfunction in babies born at home or at a PMU (Grünebaum et al., 2014) compared to births at a TMH. Arguably, the lack of an infrastructure supportive of midwifery and midwife-led, freestanding maternity units in America may explain these findings.

The study region, Counties Manukau (CM), forms one of the largest providers of birthing services within Australasia; $14 \%$ of all births in NZ are to women residing in this DHB (Jackson,
2011). It has one of the fastest growing populations in NZ with an annual growth rate of 1-2\% (Counties Manukau Health, 2016). $\mathrm{CM}$ has the second highest number of Māori (after Waikato), the highest number of Pasifika, and the second highest number of Asian people (after Auckland DHB) with a comparatively high birth rate (Winnard, Lee, \& Macleod, 2015). Of the approximate 8,500 babies born per year in the region, over $50 \%$ are born to Māori or Pasifika mothers $(24 \%$ and $32 \%$ respectively in $2007-$ 2009; Statistics New Zealand, 2018) and more than half of the birthing population for this region resides in the lowest two (9, 10) socio-economic deciles (Counties Manukau Health, 2016).

Counties Manukau District Health Board (CMH) operates a tertiary (full neonatal service) hospital as well as three PMUs. About one-third of all the low-risk women that give birth in this region use one of the three PMUs (Farry, 2015), each of which is located within a $12-40 \mathrm{~km}$ radius of the TMH. The remaining lowrisk births occur at the TMH. Midwives take primary professional responsibility for women with low-risk pregnancies during labour and birth in both the PMU and TMH unit types (Rowe, 2011; Table 1). At the time of data collection, this DHB had lower rates of LMC (community-based or self-employed) midwifery care than other regions, with the DHB providing midwifery primary maternity services (employed or core midwives) for one third of the women (Farry, 2015). To access specialist obstetric or neonatal care from a PMU, the woman or woman and baby transfer (usually via an ambulance) to the TMH with their midwife. All maternity care is fully funded for NZ residents.

\section{Our study's hypotheses}

After controlling for age, ethnicity, body mass index (BMI), parity, smoking status, and socio-economic decile, low-risk women giving birth at a PMU will have similar rates of caesarean section, blood loss and maternal postpartum admission to theatre compared with low-risk women giving birth in the TMH. Babies of lowrisk women giving birth in a PMU will have similar Apgar scores at 5-minutes and a similar number of acute neonatal admissions to intensive care when compared with babies of low-risk women giving birth in the TMH.

The maternal and neonatal outcome measures in this study are: emergency caesarean section, postpartum haemorrhage (PPH; $>500 \mathrm{ml}$ ), acute maternal postpartum admissions to theatre/high dependency unit (HDU)/intensive care (ICU; within 12 hours of birth), low Apgar (5-min Apgar <7), and acute neonatal admissions to neonatal intensive care (NICU; within 12 hours of birth).

\section{METHODS}

This retrospective cohort study compares accurately captured clinical outcomes for well ("low-risk") women giving birth in a TMH with those for women giving birth in PMUs in South Auckland, over a 12-month period. Approval was gained from local DHB and National Health Ethics Committees (expedited review number NTX/12/EXP/078). Data extraction was provided by the region's DHB data managers.

The combined birthing facilities (one TMH and three PMUs) reported 8,063 babies born during the study period. To be defined as low-risk, the woman's pregnancy was at term (37-42 weeks gestation); it was a singleton pregnancy and a cephalic presentation. Exclusion criteria were: women who had had multiple births, had been admitted to hospital during pregnancy or in labour with one or more secondary diagnostic code/s (Table 2), were induced, were $>44$ years old at time of birth or $\geq 40$ years and nulliparous at time of birth, had a BMI $>40 \mathrm{~kg} / \mathrm{m}^{2}$ at the time of booking, or who had booked $\leq 13$ days before birth (Figure 1 ). 


\begin{tabular}{|c|c|c|}
\hline Term & Definition & $\begin{array}{l}\text { Birthplace terms used } \\
\text { internationally }\end{array}$ \\
\hline $\begin{array}{l}\text { Tertiary- level obstetric-led maternity } \\
\text { hospital } \\
\text { (TMH) }\end{array}$ & $\begin{array}{l}\text { Care is provided by a team with obstetricians taking primary } \\
\text { responsibility for women at high risk of complications during labour } \\
\text { and birth. Midwives offer care to all women (high and low risk) in a } \\
\text { TMH and take primary responsibility for women with straightforward } \\
\text { pregnancies during labour and birth. Diagnostic and treatment } \\
\text { medical services (obstetric, neonatal and anaesthetic) are available } \\
\text { on site } 24 \text { hours a day. }\end{array}$ & $\begin{array}{l}\text { Tertiary hospital (NZ) } \\
\text { Conventional delivery ward } \\
\text { (Norway) } \\
\text { Hospital labour ward (Australia) } \\
\text { Standard care unit (China) } \\
\text { Standard delivery ward (Sweden) }\end{array}$ \\
\hline
\end{tabular}

\section{Table 2. Diagnostic codes indicating secondary care in pregnancy}

\begin{tabular}{|c|c|}
\hline Diagnostic code* & $n$ \\
\hline Maternal care due to uterine scar from previous surgery & 639 \\
\hline Premature rupture of membranes, onset of labour between 1-7 days later & 369 \\
\hline Preterm spontaneous labour with preterm delivery & 340 \\
\hline Duration of pregnancy $34-36$ completed weeks & 339 \\
\hline Maternal care for poor fetal growth & 337 \\
\hline Vaginal delivery following previous caesarean section & 297 \\
\hline Other specified diseases and conditions complicating pregnancy, childbirth and the puerperium & 246 \\
\hline Supervision of pregnancy with other poor reproductive or obstetric history & 218 \\
\hline Pre-eclampsia, unspecified & 190 \\
\hline Maternal care for excessive fetal growth & 189 \\
\hline Oligohydramnios & 161 \\
\hline Preterm delivery without spontaneous labour & 159 \\
\hline Antepartum haemorrhage, unspecified & 139 \\
\hline Diabetes mellitus arising during pregnancy, insulin treated & 132 \\
\hline Maternal care for breech presentation & 125 \\
\hline Duration of pregnancy $26-33$ completed weeks & 124 \\
\hline Diabetes mellitus arising during pregnancy, oral hypoglycaemic therapy & 122 \\
\hline Gestational (pregnancy-induced) hypertension without significant proteinuria & 110 \\
\hline Maternal care for other specified fetal problems & 101 \\
\hline Diabetes mellitus arising during pregnancy, other & 92 \\
\hline Endocrine, nutritional and metabolic diseases complicating pregnancy, childbirth and the puerperium & 82 \\
\hline Diseases of the digestive system complicating pregnancy, childbirth and the puerperium & 70 \\
\hline Anaemia complicating childbirth and the puerperium & 69 \\
\hline Prophylactic immunotherapy & 62 \\
\hline Polyhydramnios & 53 \\
\hline Mental disorders \& diseases of the nervous system complicating pregnancy, childbirth and the puerperium & 44 \\
\hline Other diagnostic codes e.g. rhesus isoimmunisation, thrombocytopenia, cervicalgia & 398 \\
\hline Total number of secondary diagnoses & 5,207 \\
\hline Total number of women excluded & 3,403 \\
\hline
\end{tabular}

* Diagnostic codes are not mutually exclusive, a total of 3,403 women were excluded for one or more of the above 5,207 secondary diagnoses

Women's risk status can change at any stage and their risk status on admission in labour is unknown. This fact is acknowledged as a limitation in this study.

\section{Data Extraction}

Data were collated from two DHB databases. The first was a local DHB clinical dataset entered in retrospect by non-clinical staff from contemporaneous handwritten records made by clinical staff. The second was a national patient management database updated digitally by non-clinical staff in real time and primarily used for resource allocation.
The integrity and reliability of the data were checked through comparison of the codes applied to each woman's clinical records and actual records by a clinician for a subgroup of 250 women.

The accuracy of each field was measured using the proportion of records for which the database entry matched the clinical notes. Agresti-Coull confidence intervals (CI) of 95\% (Agresti \& Coull, 1998; Brown, Cai, \& DasGupta, 2001) were used. The study was powered to produce a $95 \%$ CI of width no more than $10 \%$ under the assumption that the proportion of correct records was $80 \%$. Fields were deemed sufficiently accurate for use if the lower limit of the CI for the proportion of records correct was at 85 ). If 


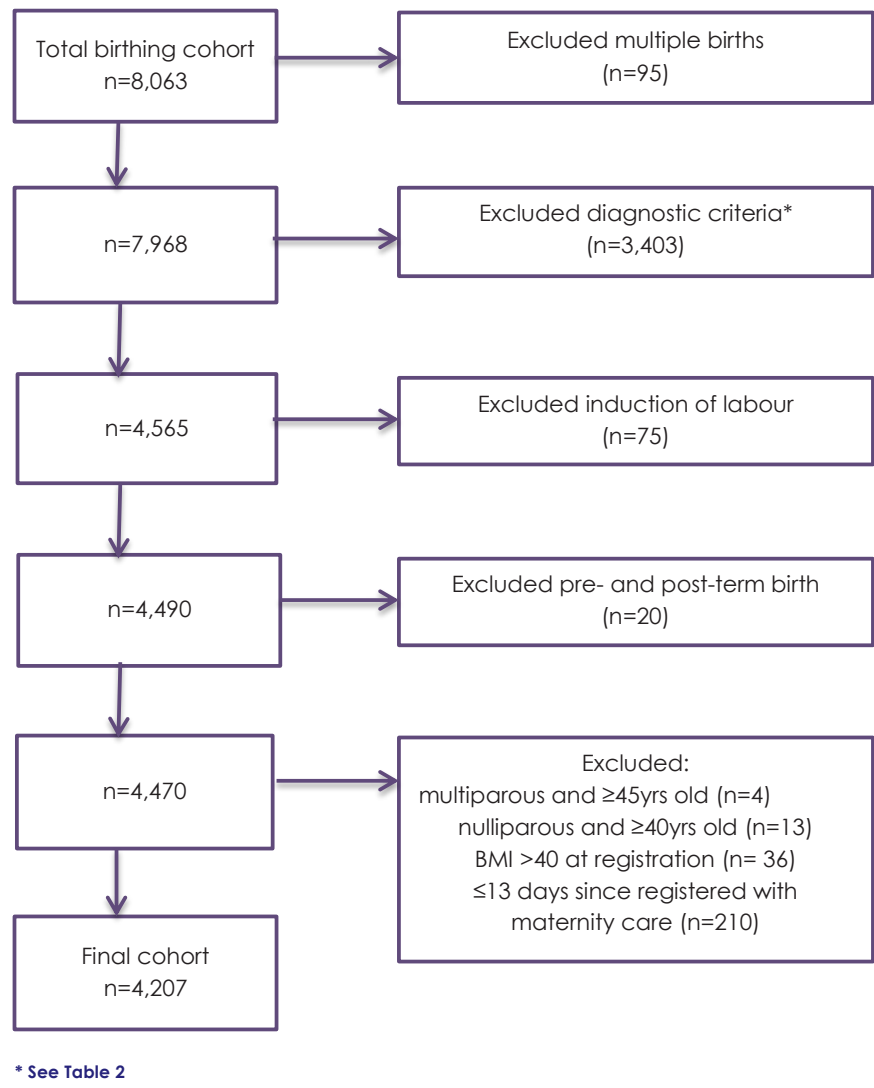

Figure 1. Flow chart inclusion/exclusion criteria to identify low risk women

this accuracy was not met, the required information was obtained from the second data source - the national patient management database. Accuracy of this database is likely to be high because it informs contemporaneous availability of beds and is a record of DHB acuity for resource management.

Of the 24 fields captured (Figure 2), five were excluded as the lower limit of the CI for the proportion of records correct was less than $85 \%$ (Table 3). Unfortunately, "Intended Place of Birth" could not be determined as women's intentions were not accurately recorded in the local database. This could have offered some insight into women's planned, compared with actual, place of birth. "Birth Site", however, was accurate and used to determine "Place of Birth". "Booking Gestation" was made accurate by subtracting the "Date of Booking" from the "EDB" (Expected Date of Birth) both $90 \%$ accurate data fields in the local database. In this way women who were booked into the Healthware database with $<13$ days left in their pregnancy could be excluded from the cohort as they no longer satisfied the low-risk criteria. This may have erroneously excluded women who were, in fact, "booked" with an LMC in a timely manner and therefore receiving antenatal care, but not booked into the Healthware database by their LMC midwife until their labour was imminent. "Location Changed" and "Changed Reason" were both inaccurate and were replaced by "Transfer Time" and "Transfer Destination" from the patient management database. This information along with "DOB Including Time" allowed intrapartum transfers to be differentiated from postpartum transfers. The data "Acute Maternal Postpartum Admission" and "Neonatal Admission" were also sourced from the national patient management database. Unfortunately, "Third Stage Procedures" did not reach the accuracy criterion and this information was not captured elsewhere, precluding this study from any deeper analysis of differences in third stage management between the sites.

\begin{tabular}{|c|c|c|}
\hline National data field & $\begin{array}{l}\text { \% Accuracy } \\
(95 \% \mathrm{Cl})\end{array}$ & $\begin{array}{l}\text { Accurate, or } \\
\text { inaccurate* }\end{array}$ \\
\hline \multicolumn{3}{|l|}{ Patient details } \\
\hline Maternal age & $97(0.95,0.99)$ & accurate \\
\hline Ethnicity & $93(0.89,0.96)$ & accurate \\
\hline Suburb & $94(0.92,0.97)$ & accurate \\
\hline \multicolumn{3}{|l|}{ Pregnancy details } \\
\hline LMP date & $97(0.95,0.99)$ & accurate \\
\hline EDB best & $98(0.96,0.99)$ & accurate \\
\hline Gravida & $97(0.95,0.99)$ & accurate \\
\hline Parity & $91(0.88,0.95)$ & accurate \\
\hline \multicolumn{3}{|l|}{ Antenatal booking } \\
\hline Smoking status & $91(0.88,0.95)$ & accurate \\
\hline Booking date & $89(0.86,0.93)$ & accurate \\
\hline Intended place of birth & $28(0.23,0.34)$ & inaccurate \\
\hline Booking gestation & $1(0,0.02)$ & inaccurate \\
\hline Maternal height & $97(0.95,0.99)$ & accurate \\
\hline Maternal weight & $95(0.93,0.98)$ & accurate \\
\hline \multicolumn{3}{|l|}{ Labour and birth (mother) } \\
\hline Birth date & $99(0.98,1)$ & accurate \\
\hline Birth method & $97(0.95,0.99)$ & accurate \\
\hline Location changed & $13(0.09,0.17)$ & inaccurate \\
\hline Changed reason & $22(0.17,0.27)$ & inaccurate \\
\hline \multicolumn{3}{|l|}{ Labour and birth (baby) } \\
\hline DOB (including time) & $99(0.98,1)$ & accurate \\
\hline Birth place & $98(0.96,0.99)$ & accurate \\
\hline Birth outcome & $99(0.98,1)$ & accurate \\
\hline \multicolumn{3}{|l|}{ Labour and birth 3rd stage } \\
\hline Estimated blood loss & $98(0.96,0.99)$ & accurate \\
\hline Third stage procedures & $87(0.83,0.91)$ & inaccurate \\
\hline \multicolumn{3}{|l|}{ Baby birth examination } \\
\hline Apgar 1 min & $96(0.94,0.98)$ & accurate \\
\hline Apgar 5 min & $97(0.95,0.99)$ & accurate \\
\hline
\end{tabular}

\section{Data Analysis}

The inferential statistical analysis was conducted using IBM SPSS version 22.0 using the protocols described by Field (2013) and Pallant (2013). Frequencies were used to describe the characteristics of all eligible healthy women with low-risk pregnancies $(n=4,207)$. Proportions and Pearson's chi-squared tests were used to explore the associations at $\mathrm{p}<0.05$ between cross-tabulated variables. Six covariates (parity, smoking status, ethnicity, BMI, socioeconomic decile, age) were identified a priori based on their suspected influence on the maternal and neonatal dependent variables (emergency caesarean section, $\mathrm{PPH}$, admission to HDU/ ICU/theatre, low Apgar, admission to NICU). These dependent variables were prepared for binary logistic regression by coding all data to dichotomous as per Bagley, White and Golomb (2001). ORs with 95\% CIs were calculated for the five perinatal outcomes and shown as unadjusted and adjusted for confounders.

\section{RESULTS}

\section{Demographics}

Fifty-two percent $(n=4,207)$ of total births in the region during the study period $(n=8,063)$ met the inclusion criteria. Of the 4,207 


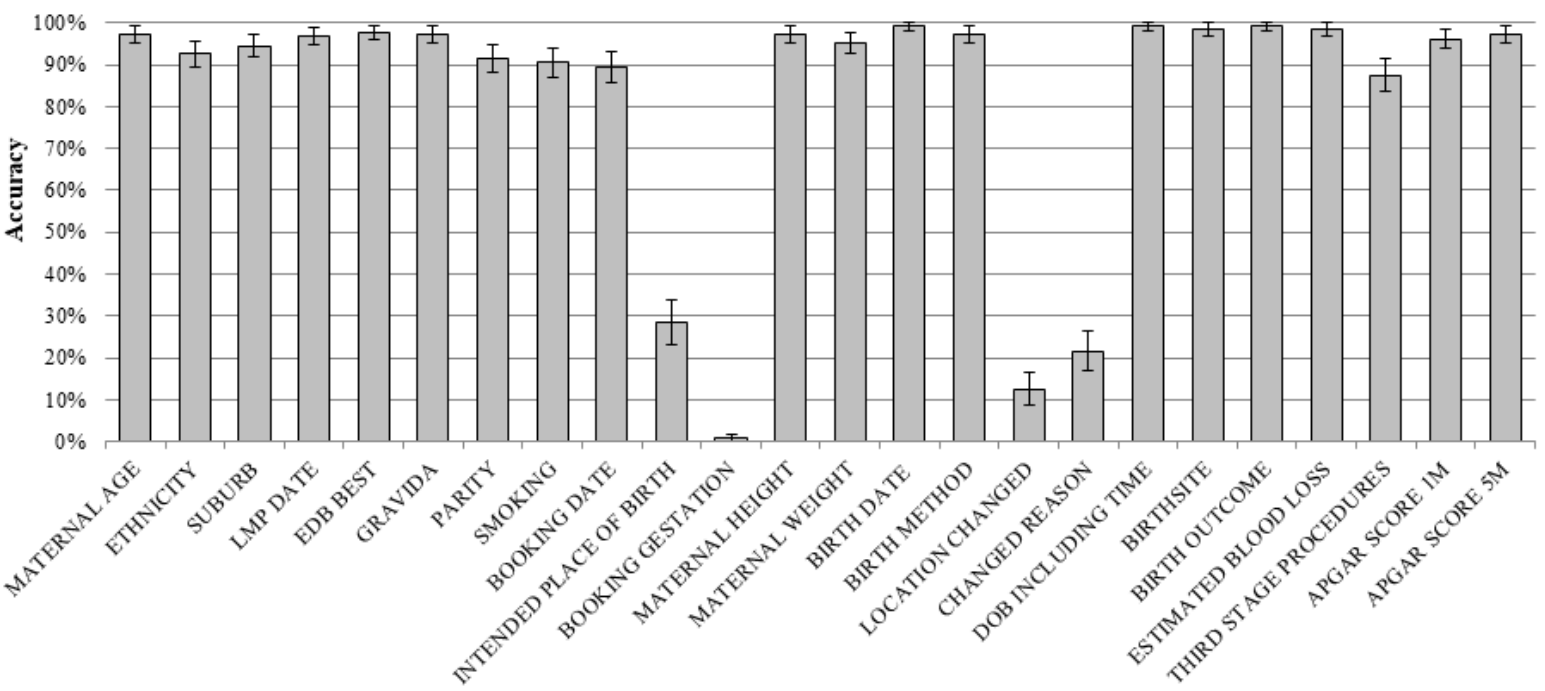

Data Field

Figure 2. Accuracy assessment of the data fields

women who met the inclusion criteria, 26.5\% ( $\mathrm{n}=1,114)$ gave birth at a PMU and $73.5 \%(\mathrm{n}=3,093)$ at the TMH. Thirty-nine percent $(n=1,206)$ of those birthing at the TMH were nulliparous, compared to $29 \%(n=323)$ of those birthing at a PMU.

The transfer rate from the three PMUs to the TMH was $6.7 \%$ for intrapartum $(\mathrm{n}=75)$ and $2.6 \%$ for immediate $(<12 \mathrm{~h})$ postpartum women $(n=29)$, making a total transfer rate of $9.3 \%$. There was a statistically significant difference $\mathrm{x}^{2}(3, \mathrm{n}=75)=65.55, \mathrm{p}<.001$ between the intrapartum transfer rate of nulliparous women $18 \%$ $(\mathrm{n}=52)$ compared to multiparous women $3 \%(\mathrm{n}=23)$. Postpartum transfers were similar between the two groups.

The maternal age, smoking status and parity profile of the PMU and TMH populations was similar. Women giving birth in the PMU were predominantly NZ European $(n=421)$ and Māori (the indigenous people of NZ; $n=359$ ), $70 \%$ combined; in contrast to the TMH which had a higher proportion of women identifying as Pacific $(n=1,348)$ and Asian $(n=509), 60 \%$ combined. Women giving birth at one of the PMUs were less likely to have a BMI $>35$ or be economically deprived. The frequency distributions of the cohort characteristics by Place of Birth are listed in Table 4.

Statistically significant interactions were identified between Place of Birth and the covariates: parity, smoking status, ethnicity, BMI, socio-economic decile, and maternal age. These confounders were adjusted for in the subsequent logistic regression analyses.

\section{Place of Birth}

The three maternal (emergency caesarean section, PPH, and acute maternal postpartum admissions) and two neonatal (Apgar and acute neonatal admission) outcomes held statistically significant associations with Place of Birth. The unadjusted and adjusted Odds Ratios (ORs) are shown in Table 5. Low-risk women giving birth at a PMU have one quarter the odds of an emergency caesarean section (aOR 0.224, 95\% CI, 0.157-0.339), half the odds of experiencing a PPH (aOR 0.536, 95\% CI, 0.424-0.676), and one fifth the odds of being acutely admitted after birth (aOR 0.201, 95\% CI, 0.1020.398) when compared to women birthing in the TMH. Babies of low-risk women giving birth in a PMU have one third the odds of receiving a low Apgar (aOR 0.354, 95\% CI, 0.135-0.926) and, correspondingly, have half the odds of being admitted to NICU (aOR 0.571, 95\% CI, 0.362-0.902), when compared to babies of low-risk women giving birth in the TMH.
Table 4. Frequency distributions of the cohort covariates for place of birth

\begin{tabular}{|c|c|c|c|c|c|c|}
\hline \multirow[b]{2}{*}{ Covariate $^{a}$} & \multirow[t]{2}{*}{ Place of Birth } & \multicolumn{2}{|c|}{ PMU } & \multicolumn{2}{|c|}{ TMH } & \multirow{2}{*}{$\begin{array}{r}\text { Pearson's } \\
\text { Chi- } \\
\text { Square }\end{array}$} \\
\hline & & n & $\%$ & n & $\%$ & \\
\hline \multirow[t]{3}{*}{ Parity ${ }^{b}$} & Multiparous & 753 & 67.6 & 1,883 & 60.9 & \multirow{3}{*}{$\begin{array}{l}n=4,207 \\
15.783 \\
p<0.001\end{array}$} \\
\hline & Nulliparous & 361 & 32.4 & 1,210 & 39.1 & \\
\hline & Total & 1,114 & 100.0 & 3,093 & 100.0 & \\
\hline \multirow[t]{3}{*}{ Smoking ${ }^{\mathrm{b}}$} & Yes & 207 & 18.6 & 486 & 15.7 & \multirow{3}{*}{$\begin{array}{l}n=4,207 \\
4.899 \\
p=0.027\end{array}$} \\
\hline & No & 907 & 81.4 & 2,607 & 84.3 & \\
\hline & Total & 1,114 & 100.0 & 3,093 & 100.0 & \\
\hline \multirow[t]{6}{*}{ Ethnicity ${ }^{b}$} & Māori & 359 & 32.3 & 640 & 20.8 & \multirow{6}{*}{$\begin{array}{l}n=4,191 \\
502.423 \\
p<0.001\end{array}$} \\
\hline & NZ European & 421 & 38.0 & 457 & 14.8 & \\
\hline & Pacific & 144 & 13.0 & 1,348 & 43.7 & \\
\hline & Asian & 113 & 10.2 & 509 & 16.5 & \\
\hline & Other & 72 & 6.5 & 128 & 4.1 & \\
\hline & Total & 1,109 & 100.0 & 3,082 & 100.0 & \\
\hline \multirow[t]{6}{*}{$\mathrm{BMI}^{\mathrm{b}}$} & $<18$ & 18 & 1.8 & 32 & 1.1 & \multirow{6}{*}{$\begin{array}{l}n=3,875 \\
50.116 \\
p<0.001\end{array}$} \\
\hline & $18-24$ & 406 & 39.8 & 999 & 35.0 & \\
\hline & $25-29$ & 328 & 32.1 & 787 & 27.6 & \\
\hline & $30-34$ & 188 & 18.4 & 596 & 20.9 & \\
\hline & $35-40$ & 79 & 7.8 & 442 & 15.4 & \\
\hline & Total & 1,019 & 100.0 & 2,856 & 100.0 & \\
\hline \multirow{3}{*}{$\begin{array}{l}\text { Socio-economic } \\
\text { decileb,c }\end{array}$} & $1-5$ & 368 & 35.7 & 487 & 16.5 & \multirow{3}{*}{$\begin{array}{l}n=3,970 \\
223.550 \\
p<0.001\end{array}$} \\
\hline & $6-10$ & 664 & 64.3 & 2,451 & 83.4 & \\
\hline & Total & 1,032 & 100.0 & 2,938 & 100.0 & \\
\hline \multirow[t]{4}{*}{$\mathrm{Age}^{\mathrm{b}}$} & $15-24$ & 364 & 32.6 & 1,277 & 41.2 & \multirow{4}{*}{$\begin{array}{l}n=4,207 \\
20.328 \\
p<0.001\end{array}$} \\
\hline & $25-34$ & 600 & 53.9 & 1,477 & 47.7 & \\
\hline & $35-44^{d}$ & 150 & 13.5 & 339 & 11.0 & \\
\hline & Total & 1,114 & 100.0 & 3,093 & 100.0 & \\
\hline \multirow[t]{3}{*}{ Model of Care } & DHB & 397 & 35.7 & 1,172 & 38.0 & \multirow{3}{*}{$\begin{array}{l}n=4,198 \\
1.810 \\
p=0.179\end{array}$} \\
\hline & LMC & 715 & 64.3 & 1,914 & 62.0 & \\
\hline & Total & 1,112 & 100.0 & 3,086 & 100.0 & \\
\hline
\end{tabular}

a $\mathrm{n}$ differs for some confounders due to missing data in the original data set

${ }^{b}$ Confounding covariates adjusted for in the logistic regressions presented in Table 5

c The higher the decile, the greater the socio-economic deprivation

a Only multiparous women were included $>40$ years of age 


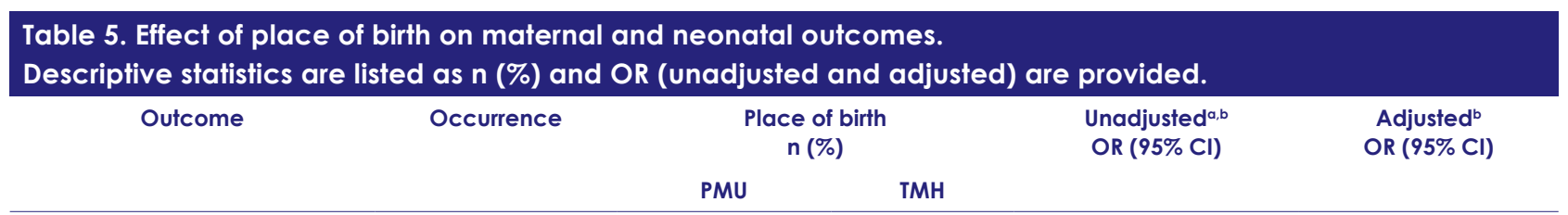

\begin{tabular}{|c|c|c|c|c|c|}
\hline \multicolumn{6}{|l|}{ Maternal } \\
\hline \multirow[t]{3}{*}{ Emergency caesarean section } & $\mathrm{No}^{\mathrm{c}}$ & $1,092(98.2)$ & $2,856(92.5)$ & \multirow{3}{*}{$0.224(0.141-0.356)$} & \multirow{3}{*}{$0.250(0.157-0.339)$} \\
\hline & & & & & \\
\hline & Yes & $20(1.8)$ & $233(7.5)$ & & \\
\hline \multirow[t]{2}{*}{ Postpartum haemorrhage } & No & $1,007(92.2 \%)$ & $2,481(87.0 \%)$ & \multirow{2}{*}{$0.489(0.389-0.615)$} & \multirow{2}{*}{$0.536(0.424-0.676)$} \\
\hline & Yes & $85(7.8 \%)$ & $371(13.0 \%)$ & & \\
\hline \multirow{2}{*}{$\begin{array}{l}\text { Acute postpartum admission } \\
\text { to HDU/ICU/theatre }\end{array}$} & No & $1,105(99.2 \%)$ & 2,967 (95.9\%) & \multirow{2}{*}{$0.192(0.097-0.378)$} & \multirow{2}{*}{$0.201(0.102-0.398)$} \\
\hline & Yes & $85(7.8 \%)$ & 371 (13.0\%) & & \\
\hline \multicolumn{6}{|l|}{ Neonatal } \\
\hline \multirow{2}{*}{$\begin{array}{l}\text { Low Apgar } \\
<7 \text { at } 5 \text { min }\end{array}$} & No & $1,106(99.5 \%)$ & $3,032(98.5 \%)$ & \multirow{2}{*}{$0.298(0.118-0.752)$} & \multirow{2}{*}{$0.354(0.135-0.926)$} \\
\hline & Yes & $5(0.5 \%)$ & $46(1.5 \%)$ & & \\
\hline \multirow[t]{2}{*}{ Neonatal admission to NICU } & No & $1,087(97.6 \%)$ & $2,940(95.1 \%)$ & & \\
\hline & Yes & $27(2.4 \%)$ & $150(4.9 \%)$ & $0.477(0.315-0.723)$ & $0.571(0.362-0.902)$ \\
\hline
\end{tabular}

a All results were statistically significant at $p<0.001$

b Adjusted for parity, smoking status, ethnicity, BMI, socio-economic decile, and age, as per Table 4

$c$ This outcome describes vaginal birth inclusive of instrumental birth

When the number of women who required a caesarean section $(n=253)$ was removed from the cohort, the proportion of women experiencing a $\mathrm{PPH}$ in the TMH was still statistically significantly higher than the proportion of those who had a $\mathrm{PPH}$ and whose Place of Birth was a PMU (OR 0.692, 95\% CI, 0.534-0.898). In addition, the non-caesarean section babies born in the TMH remained more likely to be admitted to NICU (OR 0.168, 95\% CI, 0.082-0.345).

There were no incidences of maternal or neonatal mortality reported in either cohort.

\section{DISCUSSION}

This study found that women giving birth in a freestanding PMU had more favourable clinical outcomes when compared with women giving birth in a TMH. The findings identify statistically significant differences in outcomes dependent on the place of birth, with women giving birth in a freestanding PMU having lower odds of emergency caesarean section, PPH, and acute maternal postpartum admissions to theatre/HDU/ICU, and their babies having lower odds of an Apgar $<7$ at 5 minutes and of acute neonatal admission to NICU. The associations remained significant after adjustment for known confounding factors (age, ethnicity, decile, BMI, smoking status and parity). For low-risk women giving birth at the TMH, the odds of an emergency caesarean section were four times the odds of women birthing at the PMUs, and the odds of acute maternal postpartum admission to theatre/HDU/ICU were five times the odds of women birthing at the PMUs. This latter finding may reflect the morbidity associated with caesarean (Gregory, Jackson, Korst, \& Fridman, 2012) and the increase in prevalence of epidural, episiotomy, and forceps, leading to a higher rate of third and fourth degree tears (Fitzgerald et al., 2007) in the TMH.

The number of women experiencing a $\mathrm{PPH}$ was found to be significantly less for PMU births compared with TMH births. This differs from the results in a study undertaken by Davis et al. (2011) which compared outcomes for place of birth. In their study the place of birth was not found to have a significant effect on maternal blood loss. However, their study defined women experiencing a PPH as having a blood loss $>1,000 \mathrm{ml}$ which they argued to be a clearer indication of morbidity. In our study, a blood loss of more than $500 \mathrm{ml}$ was the measure identified to determine PPH. This was because Conner et al. (2015) found that the thresholds most predictive of a clinically significant estimated blood loss were confirmed to be $500 \mathrm{ml}$ in a vaginal birth and $1,000 \mathrm{ml}$ in a caesarean section, with the median recorded blood loss resulting from a caesarean section being $500 \mathrm{ml}$. To determine if $\mathrm{PPH}$ was an interaction of the increased number of emergency caesarean sections observed, we undertook a subgroup analysis in which women whose labours resulted in an emergency caesarean section were removed. We found that the incidence of $\mathrm{PPH}$ remained significantly lower when women gave birth at a PMU. Oxytocin augmentation during labour has been shown to increase the risk of PPH (Belghiti et al., 2011; Combs, Murphy, \& Laros, 1991; Grotegut, Paglia, Johnson, Thames, \& James, 2011; Sheiner, Sarid, Levy, Seidman, \& Hallak, 2005; Waterstone, Bewley, \& Wolfe, 2001), perhaps by desensitising receptors (Phaneuf et al., 1998; Robinson, Schumann, Zhang, \& Young, 2003), thereby impairing oxytocin's post-delivery effects on uterine contractility and increasing the risk of atonic PPH (Magalhaes et al., 2009). Oxytocin augmentation does not occur at PMUs and this may explain the difference in blood loss between the two sites.

The higher rate of neonatal admission of babies of women birthing in the TMH in this study was in agreement with the large Birthplace in England study (Hollowell et al., 2011), two Australian studies (Laws et al., 2010; Monk et al., 2014) and two previous NZ studies (Bailey, 2017; Davis et al., 2011). These findings indicate that routine hospital birth is not safer for babies of low-risk mothers. The higher number of NICU admissions, in the cohort excluding caesarean section, remained significant for women birthing vaginally at the TMH. This agrees with Laws et al. (2010) and Davis et al. (2011), where increased rate of admission to NICU was associated with labour interventions and assisted modes of birth in the TMH settings they studied.

There is no equivalent low-risk national dataset with which to compare and identify the generalisability of our study sample. The demographic findings demonstrate that our sample held 
similarities to national maternity data (Ministry of Health, 2017). Age, nulliparity, smoking status, and ethnicity (NZ Māori, Asian and Other) were all within $1-2 \%$ of the national/regional maternity data. The proportion of women identifying themselves as NZ European was higher in the national maternity data (48\%), than in the current study cohort $(20.9 \%)$. The proportion of women identifying themselves as Pacific was lower in the National Maternity data (11.2\%) than the current study cohort (35.5\%). Socio-economic decile is comparable between this study's use of "deprivation decile" and the nationally gathered data reported as "deprivation quintile" according to Atkinson, Salmond and Crampton (2014). The National Report on Maternity (2015) states that $29.8 \%$ of NZ birthing women reside in quintile 5 (the lowest quintile in NZ). This study reports $54.2 \%$ of the cohort reside in decile 9, 10 (the lowest two deciles). It is possible to conclude that this cohort is more deprived than the national average. The most recent annual report to the National Maternity Quality and Safety Programme also revealed that more than half of the entire Counties Manukau birthing population for this region resides in the lowest two $(9,10)$ socio-economic deciles (Counties Manukau Health, 2016).

\section{Rates of transfer}

The intrapartum and immediate postpartum (within 12 hours of birth) transfer rate was $9.3 \%(\mathrm{n}=104)$, lower than the $19 \%$ $(\mathrm{n}=6002), 21.9 \% \quad(\mathrm{n}=2,468)$ and $17.3 \% \quad(\mathrm{n}=70)$ reported by Bailey (2017), Hollowell et al. (2011) and Grigg et al. (2017), respectively. However, these studies either included maternal and neonatal transfers up to 48 hours (Grigg et al., 2017) or did not define the timeframe (Bailey, 2017; Hollowell et al., 2011). Sixty-nine percent of the transfers were primigravid women. This rate sits between that found by the other two NZ studies which reported a transfer rate of primigravid women of $96.3 \%$ (Grigg, Tracy, Tracy, Schmied, \& Monk, 2015) and 39\% (Bailey, 2017). The latter study may be more relevant as the data are from the same region. However, it may be that the accuracy of manual calculation of data sourced through the national patient management database reveals a more accurate picture of intrapartum transfer. The source of transfer data is not reported by Bailey (2017). The accuracy assessment carried out in this study would suggest that if Healthware data were used they would provide inaccurate figures.

Our study adds to the body of evidence demonstrating that when women give birth in a PMU they have less intervention than when they birth in a TMH. Despite these findings the majority of women continue to choose to birth in a TMH. The notion of informed choice is one of the guiding principles of the midwife-woman partnership in NZ (New Zealand College of Midwives, 2015). Informed choice means that through discussion, education and the sharing of evidence, a woman is able to decide what best serves her needs. To reduce (or at least stabilise) the continually rising rate of caesarean sections, this research suggests that the option of giving birth in a PMU needs to be actively discussed, disseminated and promoted to low-risk women and their support people.

A recent study which surveyed women's wishes around place of birth in Christchurch, NZ, found that perceived risk strongly influenced the woman's decision to birth in a TMH, while a combination of proximity, comfort and avoidance of intervention strongly influenced the woman's decision to birth in a PMU (Grigg et al., 2014). Further research is needed to explore the perception of safety and place of birth as barriers to women choosing a PMU. In addition to ensuring information is shared with women, there is a need to consider the role of the clinician in decision making. Davis and Homer (2016) recently explored why some midwives use different birthing environments and found "that the culture of the birthplace rather than the physicality is the highest priority" (p.414). It has been suggested that TMHs are structured and function in ways that make childbearing women and midwives change their behaviour. This behaviour difference, termed submissiveness by Fahy and Parratt (2006), is theorised to weaken autonomy for both childbearing women and midwives. Previous $\mathrm{NZ}$ research has shown the influence of organisational context on practice (Davis \& Walker, 2010; Miller \& Skinner, 2012). This is an important issue to consider when looking to support midwives to work in PMUs. Midwives have concerns related to their own professional safety and support needs. The United Kingdom has incorporated changes in their intrapartum care guidelines (National Institute for Health and Clinical Excellence (NICE), 2014) advising health practitioners to offer birth at midwiferyled units to low-risk women. This formal requirement provides implied support for the practitioner to practise in PMUs; however, for midwives who have mostly practised in TMHs, moving to a PMU could be considered challenging. Women, and perhaps midwives, make their choices based on their personal perception of safety and therefore changing these perceptions may be difficult. More research is needed to identify what support structures are needed both for women to utilise, and midwives to facilitate birth in, PMUs.

It may not be advisable to extrapolate these findings to other regions. The freestanding PMUs in this study were relatively busy, with on site midwives present at all times and located within 45 minutes by road from the TMH. Some NZ PMUs are several hours from the hospital and not all have midwives present at all times. Most pregnant women in NZ are under the care of selfemployed midwives who have continuous access to obstetric services, facilitating safe and timely consultation and transfer. This requires a strong midwifery infrastructure that may be lacking in other countries.

\section{Strengths and limitations}

This study was undertaken in an area of high deprivation, which is associated with poorer outcomes, yet the findings support PMUs as being safer than the TMH for this population. This study involved a rigorous accuracy assessment process which helped to identify and determine the most robust data fields for analysis. In addition, the comprehensive inclusion/exclusion criteria identified a sample of low-risk women. However, only risk factors requiring hospitalisation were captured by the diagnostic codes and therefore there may have been some higher risk women (being managed as outpatients) who were included, leading to potential sample bias. Apart from women's antenatal risk, women's risk status on admission in labour cannot be identified, and this absence of information constitutes another potential source of sample bias. Women with meconium liquor, Group B Strep, fetal heart rate abnormality on home assessment, maternal fever, or long latent phase needing analgesia have all been found to be reasons for a change of plan prior to admission in labour (Grigg, Tracy, Schmied, Monk, \& Tracy, 2015). These women would all be admitted to the TMH and their higher risk status would not be identified by the exclusion criteria we used. Another limitation is that the size of the cohort was insufficient to detect rare and severe outcomes in either setting (as there were none). In addition, women's choice is paramount in our model of maternity care and this may have led to differences in philosophy, values and beliefs which also could have had an effect on where women chose to give birth. It is difficult to identify this construct or determine its effect. 


\section{CONCLUSIONS}

This research found evidence for increased risk of adverse outcomes for low-risk births at an obstetric-led tertiary level maternity hospital (TMH) compared to freestanding primary level midwife-led maternity units (PMUs) in South Auckland, NZ. This research adds to the growing body of international research on freestanding PMUs, confirming them as physically safe places for well women to give birth when midwifery is properly integrated into the maternity system, allowing for the provision of continuity of care across sites and timely referral. The task now is to protect the unique relationship between the TMH and the PMUs of South Auckland and to promote similar models across the country and around the world. This can be achieved by healthcare policy makers and maternity care providers publicly acknowledging the benefits PMUs provide childbearing women and their families. Dissemination and advocation of the findings from this research, along with similar national and international primary maternity unit birthplace literature, are highly recommended.

\section{ACKNOWLEDGEMENTS AND CONFLICT OF INTEREST DISCLOSURE}

The authors would like to acknowledge Debra Fenton, Sharon Arrol, Keming Wang, Cindy Taylor and Erin Hanlon for their help with accessing, editing and interpreting the data.

The authors declare that there are no conflicts of interest.

\section{REFERENCES}

Agresti, A., \& Coull, B.A. (1998). Approximate is better than "exact" for interval estimation of binomial proportions. The American Statistician, 52(2), 119-126. doi:10.1080/00031305.1998.10480550

Atkinson, J., Salmond, C., \& Crampton, P. (2014). Socioeconomic Deprivation Indexes: NZDep and NZiDep. Retrieved from http://www. otago.ac.nz/wellington/research/hirp/otago020194.html

Bagley, S.C., White, H., \& Golomb, B.A. (2001). Logistic regression in the medical literature: Standards for use and reporting, with particular attention to one medical domain. Journal of Clinical Epidemiology, 54(10), 979-985. doi:10.1016/S0895-4356(01)00372-9

Bailey, D.J. (2017). Birth outcomes for women using free-standing birth centers in South Auckland, New Zealand. Birth, 44(3), 246-251. doi: 10.1111/birt.12287

Belghiti, J., Kayem, G., Dupont, C., Rudigoz, R.-C., Bouvier-Colle, M.-H., \& Deneux-Tharaux, C. (2011). Oxytocin during labour and risk of severe postpartum haemorrhage: A population-based, cohortnested case-control study. BMJ Open, 1(2), e000514. doi:10.1136/ bmjopen-2011-000514

Brown, L.D., Cai, T.T., \& DasGupta, A. (2001). Interval estimation for a binomial proportion. Statistical Science, 16(2), 101-133. doi:10.1214/ ss/1009213286

Combs, C.A., Murphy, E.L., \& Laros, R.K., Jr. (1991). Factors associated with postpartum hemorrhage with vaginal birth. Obstetrics \& Gynecology, 77(1), 69-76.

Conner, S., Tuuli, M., Colvin, R., Shanks, A., Macones, G., \& Cahill, A. (2015). Accuracy of estimated blood loss in predicting need for transfusion after delivery. American Journal of Perinatology, 32(13), 1225-1230. doi:10.1055/s-0035-1552940.

Counties Manukau Health. (2016). Maternity Quality and Safety Programme: Annual Report 2015-2016. Retrieved from https:// issuu.com/communicationsmiddlemore/docs/cmh_mqsp_annual_ report_2015_2016_f

Davis, D.L., Baddock, S., Pairman, S., Hunter, M., Benn, C., Wilson, D., ... Herbison, P. (2011). Planned place of birth in New Zealand: Does it affect mode of birth and intervention rates among low-risk women? Birth, 38(2), 111-119. doi:10.1111/j.1523-536X.2010.00458.x Davis, D.L., \& Homer, C.S.E. (2016). Birthplace as the midwife's work place: How does place of birth impact on midwives? Women and Birth, 29(5), 407-415. doi:10.1016/j.wombi.2016.02.004

Davis, D.L., \& Walker, K. (2010). Case-loading midwifery in New Zealand: Making space for childbirth. Midwifery, 26(6), 603-608. doi:10.1016/j.midw.2009.01.004
Fahy, K.M., \& Parratt, J.A. (2006). Birth Territory: A theory for midwifery practice. Women and Birth, 19(2), 45-50. doi:10.1016/j. wombi.2006.05.001

Farry, A. (2015). A retrospective cohort study to evaluate the effect of 'Place Presenting in Labour' and 'Model of Midwifery Care' on maternal and neonatal outcomes for the low risk women birthing in Counties Manukau District Health Board facilities 2011-2012. (Master's thesis). Auckland Universtiy of Technology, Auckland. Retrieved from http://aut. researchgateway.ac.nz/handle/10292/9467.

Field, A.P. (2013). Discovering statistics using IBM SPSS Statistics: and sex and drugs and rock ' $n$ ' roll. Los Angeles: Sage.

Fitzgerald, M.P., Weber, A.M., Howden, N., Cundiff, G.W., Brown, M.B., \& Pelvic Floor Disorders Network. (2007). Risk factors for anal sphincter tear during vaginal delivery. Obstetrics and Gynecology, 109(1), 29-34. doi:10.1097/01.AOG.0000242616.56617.ff

Gregory, K.D., Jackson, S., Korst, L., \& Fridman, M. (2012). Cesarean versus vaginal delivery: Whose risks? Whose benefits? American Journal of Perinatology, 29(1), 7-18. doi:10.1055/s-0031-1285829

Grigg, C.P., Tracy, S.K., Daellenbach, R., Kensington, M., \& Schmied, V. (2014). An exploration of influences on women's birthplace decisionmaking in New Zealand: A mixed methods prospective cohort within the Evaluating Maternity Units study. BMC Pregnancy and Childbirth, 14(1), 210. doi:10.1186/1471-2393-14-210

Grigg, C.P., Tracy, S.K., Schmied, V., Monk, A., \& Tracy, M.B. (2015). Women's experiences of transfer from primary maternity unit to tertiary hospital in New Zealand: Part of the prospective cohort Evaluating Maternity Units study. BMC Pregnancy \& Childbirth, 15, 1-12. doi:10.1186/s12884-015-0770-2

Grigg, C.P., Tracy, S.K., Tracy, M., Schmied, V., \& Monk, A. (2015). Transfer from primary maternity unit to tertiary hospital in New Zealand - timing, frequency, reasons, urgency and outcomes: Part of the Evaluating Maternity Units study. Midwifery, 31(9), 879-887. doi:https://doi.org/10.1016/j.midw.2015.04.018

Grigg, C.P., Tracy, S.K., Tracy, M.B., Daellenbach, R., Kensington, M., Monk, A., \& Schmied, V. (2017). Evaluating Maternity Units: A prospective cohort study of freestanding midwife-led primary maternity units in New Zealand - clinical outcomes. BMJ Open, 7(8), e016288. doi:10.1136/bmjopen-2017-016288

Grotegut, C.A., Paglia, M.J., Johnson, L.N., Thames, B., \& James, A.H. (2011). Oxytocin exposure during labor among women with postpartum hemorrhage secondary to uterine atony. American Journal of Obstetrics \& Gynecology, 204(1), 56.e51-56. doi:10.1016/j.ajog.2010.08.023

Grünebaum, A., McCullough, L.B., Sapra, K.J., Brent, R.L., Levene, M.I., Arabin, B., \& Chervenak, F.A. (2014). Early and total neonatal mortality in relation to birth setting in the United States, 2006-2009. American Journal of Obstetrics \& Gynecology, 211(4), 390.e391-390.e397. doi:10.1016/j.ajog.2014.03.047

Hollowell, J., Puddicombe, D., Rowe, R., Linsell, L., Hardy, P., Stewart, M., ... Brocklehurst, P. (2011). The Birthplace national prospective cohort study: Perinatal and maternal outcomes by planned place of birth. Oxford, UK: NIHR Service Delivery and Organisation programme.

Homer, C.S.E., Thornton, C., Scarf, V.L., Ellwood, D.A., Oats, J.J.N., Foureur, M.J., . . Dahlen, H.G. (2014). Birthplace in New South Wales, Australia: An analysis of perinatal outcomes using routinely collected data. BMC Pregnancy and Childbirth, 14(1), 206. doi:10.1186/1471-2393-14-206

Jackson, C. (2011). Antenatal care in Counties Manukau DHB: A focus on primary antenatal care. Retrieved from https://www.countiesmanukau. health.nz/assets/About-CMH/Performance-and-planning/healthstatus/2011-antenatal-care-CMDHB.pdf

Laws, P.J., Tracy, S.K., \& Sullivan, E.A. (2010). Perinatal outcomes of women intending to give birth in birth centers in Australia. Birth: Issues in Perinatal Care, 37(1), 28-36. doi:10.1111/j.1523-536X.2009.00375.x

Magalhaes, J.K., Carvalho, J.C., Parkes, R.K., Kingdom, J., Li, Y., \& Balki, M. (2009). Oxytocin pretreatment decreases oxytocin-induced myometrial contractions in pregnant rats in a concentration-dependent but not time-dependent manner. Reproductive Sciences, 16(5), 501-508. doi:10.1177/1933719108329954

Miller, S., \& Skinner, J. (2012). Are first-time mothers who plan home birth more likely to receive evidence-based care? A comparative study of home and hospital care provided by the same midwives. Birth, 39(2), 135-144. doi:10.1111/j.1523-536X.2012.00534.x

Ministry of Health. (2007). Primary Maternity Services Notice (pursuant to Section 88 of the New Zealand Public Health \& Disability Act 2000). 
Retrieved from https://www.health.govt.nz/publication/primarymaternity-services-notice-2007

Ministry of Health. (2015). Report on Maternity, 2012. Retrieved from https://www.health.govt.nz/publication/report-maternity-2012

Ministry of Health. (2017). Report on Maternity, 2015. Retrieved from https://www.health.govt.nz/publication/report-maternity-2015

Monk, A., Tracy, M.B., Foureur, M., Grigg, C.P., \& Tracy, S.K.

(2014). Evaluating Midwifery Units (EMU): A prospective cohort study of freestanding midwifery units in New South Wales, Australia. BMJ Open, 4(10), e006252. doi:10.1136/bmjopen-2014-006252

National Institute for Health and Clinical Excellence (NICE). (2014). Intrapartum Care: Care of healthy women and their babies during childbirth. Retrieved from http://www.nice.org.uk/nicemedia/pdf/ IPCNICEGuidance.pdf. .

New Zealand College of Midwives. (2015). Midwives handbook for practice. Christchurch: Author.

Overgaard, C., Møller, A.M., Fenger-Grøn, M., Knudsen, L.B., \& Sandall, J. (2011). Freestanding midwifery unit versus obstetric unit: A matched cohort study of outcomes in low-risk women. BMJ Open, 1(2), e000262.

Pallant, J. (2013). SPSS survival manual: A Step by step guide to data analysis using IBM SPSS. Maidenhead, England: McGraw Hill.

Phaneuf, S., Asbóth, G., Carrasco, M.P., Liñares, B.R., Kimura, T., Harris, A., \& Bernal, A.L. (1998). Desensitization of oxytocin receptors in human myometrium. Human Reproduction Update, 4(5), 625-633. doi:10.1093/humupd/4.5.625

Robinson, C., Schumann, R., Zhang, P., \& Young, R.C. (2003).

Oxytocin-induced desensitization of the oxytocin receptor. American Journal of Obstetrics \& Gynecology, 188(2), 497-502.

Rowe, R.E. (2011). Birthplace terms and definitions: Consensus process Birthplace in England research programme. Final report part 2. Retrieved from http://www.netscc.ac.uk/hsdr/files/project/SDO_FR2_08-1604140_V02.pdf

Schroeder, E., Petrou, S., Patel, N., Hollowell, J., Puddicombe, D., Redshaw, M., \& Brocklehurst, P. (2012). Cost effectiveness of alternative planned places of birth in woman at low risk of complications: Evidence from the Birthplace in England national prospective cohort study. BMJ, 344. doi:10.1136/bmj.e2292

Sheiner, E., Sarid, L., Levy, A., Seidman, D.S., \& Hallak, M. (2005). Obstetric risk factors and outcome of pregnancies complicated with early postpartum hemorrhage: A population-based study. The Journal of Maternal-Fetal \& Neonatal Medicine, 18(3), 149-154. doi:10.1080/14767050500170088

Stapleton, S.R., Osborne, C., \& Illuzzi, J. (2013). Outcomes of care in birth centers: Demonstration of a durable model. Journal of Midwifery \& Women's Health, 58(1), 3-14. doi:https://doi.org/10.1111/jmwh.12003

Statistics New Zealand. (2018). Births and deaths: Year ended December 2017. Retrieved from https://www.stats.govt.nz/information-releases/ births-and-deaths-year-ended-december-2017

Waterstone, M., Bewley, S., \& Wolfe, C. (2001). Incidence and predictors of severe obstetric morbidity: Case-control study. BMJ, 322(7294), 1089-1093. doi:10.1136/bmj.322.7294.1089

Wax, J.R., Lucas, F.L., Lamont, M., Pinette, M.G., Cartin, A., \& Blackstone, J. (2010). Maternal and newborn outcomes in planned home birth vs planned hospital births: A metaanalysis. American Journal of Obstetrics and Gynecology, 203(3), 243.e1-8. doi:10.1016/j.ajog.2010.05.028

Wiegerinck, M.M., van der Goes, B.Y., Ravelli, A.C., van der Post, J.A., Klinkert, J., Brandenbarg, J., ... Mol, B.W. (2015). Intrapartum and neonatal mortality in primary midwife-led and secondary obstetrician-led care in the Amsterdam region of the Netherlands: A retrospective cohort study. Midwifery, 31(12), 1168-1176. doi:10.1016/j.midw.2015.08.007 Winnard, D., Lee, M., \& Macleod, G. (2015). Demographic profile: 2013 census, population of Counties Manukau. Retrieved from http://www. countiesmanukau.health.nz/assets/About-CMH/Demographics-andpopulations/Census-2013-profile-for-residents-of-Counties-Manukau.pdf Accepted for Publication January 2019

Farry, A., McAra-Couper, J., Weldon, M.C., \& Clemons, J. (2019). Comparing perinatal outcomes for healthy pregnant women presenting at primary and tertiary settings in South Auckland: A retrospective cohort study. New Zealand College of Midwives Journal, 55, 5-13. https://doi.org/10.12784/nzcomjnl55.2019.1.5-13 